\title{
Development of a Combustion Delay Model in the Control of Innovative Combustions
}

\author{
Marco Abbondanza, Nicolò Cavina, Enrico Corti ${ }^{1}$, Davide Moro, Fabrizio Ponti and Vittorio \\ Ravaglioli
}

Dept. of Industrial Engineering, University of Bologna, Viale del Risorgimento, 2, Bologna, Italy

\begin{abstract}
In modern internal combustion engines the research for innovative solutions aimed at the simultaneous reduction of engine-out pollutants and fuel consumption requires synergies from different application areas: the thermo-fluid dynamic design of the combustion chamber, the study and production of specific components for air and fuel supply, the development of sensors and related methods of analyzing their signals to control the combustion process. The most promising innovative combustion methodologies suitable to achieve high efficiency and low emissions, commonly named Low Temperature Combustions (LTC), usually require sophisticated techniques for the management of the combustion phase. With respect to the combustion angular position control, directly performed in traditional spark ignition engines through the ignition from the spark plug and in compression ignition engines by the timing of fuel injection, the ignition mechanisms of LTC combustions are characterized by a high sensitivity to the thermal conditions of the combustion chamber which greatly modifies the angular position of the combustion, mainly due to the combination of high ignition delays and lean homogeneous mixture. Once the hardware of the air and fuel supply systems has been defined, it is therefore essential to ensure the correct management of the combustion phase.

In this paper a model for the estimation of the delay between the start of injection and the start of combustion is presented. The model has been developed analyzing the experimental data from a modified cylinder of a diesel engine, fueled with gasoline, while the other three cylinders were still running with Diesel fuel. This solution represents a first step that allows analyzing the behavior of the combustion of gasoline in a Diesel engine, with the final goal to inject gasoline in all the engine cylinders. In particular, the approach used is similar to the one already applied in a traditional turbocharged gasoline engine, where the goal was to estimate the time delay between the spark firing and the start of combustion, mainly to detect the presence of undesired pre-ignition due to the presence of hot spots related to slightly knocking conditions. As it is well known, the role of the pilot injection is to reduce the ignition delay of the main injection. However, to significantly accelerate the ignition of the fuel injected with the main injection, it is necessary to burn a sufficient quantity of the fuel injected by the pilot before the Top Dead Center position (TDC). The application of this model has to allow the implementation of a feed-forward control to stabilize
\end{abstract}

\footnotetext{
${ }^{1}$ Corresponding author: enrico.corti2@unibo.it
} 
the whole combustion process and achieve the best conversion efficiency from energy to work, taking into account the operational constraints that must be satisfied to guarantee the integrity of the engine and the compliance with the homologation rules.

\section{Introduction}

The continuously increasing request for higher engine efficiency and lower harmful emissions in the last decades has spurred the researchers involved in internal combustion engines development to look for new innovative solutions to meet these targets. The most promising technique to achieve these targets seems to be the introduction of LTC methodologies, which show a very interesting pollutant emissions reduction potential, mainly in terms of nitrogen oxide and soot $(1,2)$. Hundreds of papers have presented results about the performance, the different typologies of combustion, the different fuel mixture behavior and the analysis of the physical quantities and phenomena affecting such type of combustion. The most promising technologies seem to be those based on dual fuel systems or single fuel with split injections to obtain an effective control of the combustion angular position in engines with compression ignition (3-7).

Even if there is a huge and deep activity of research both from university and industrial research centers, the large-scale application and industrial exploitation of these low temperature combustion engines is still limited. The main reason of the retard for the industrialization of these techniques is the necessity to develop a cheap closed-loop control of the combustion process that presents a non-linear behavior moving from low to high load $(8,9)$. To achieve this goal, it is necessary to utilize direct or indirect information about the combustion process behavior and its phasing, analyzing in real time data acquired form the engine with low cost sensors (10). In Gasoline Direct injection Compression Ignition (GDCI) combustion systems a fundamental role is played by the combustion of the gasoline pilot injection, that must prepare the proper thermodynamic condition which guarantees the robust control of the following combustion phasing, i.e. assuring that the start of the main combustion occurs in close angular relation with its injection position (11-13). This allows a better control of the optimal angular position of the $50 \%$ of mass fuel burned, taking under control also the pressure gradient and the value of the maximum pressure and temperature peaks that influence the nitrogen oxides $\left(\mathrm{NO}_{\mathrm{x}}\right)$ formation. The authors believe that the knowledge by means of a black box model of the delay between the start of injection (SOI) of small amount of fuel (so called pilot injection) and its start of combustion (SOC) can represent an important step towards a more robust control strategy with a higher degree of repeatability $(14,15)$.

The first part of the paper presents the approach to estimate the delay between the pilot injection and its start of combustion in a turbocharged diesel engine fueled with gasoline. The advantages of this engine solution are multiple: the higher compression ratio allows higher efficiency with respect to traditional gasoline engines, the replacement of diesel fuel with gasoline reduces particulate matter, while the more homogeneous lean mixture allows limiting the local temperature peaks, therefore decreasing the formation of $\mathrm{NO}_{\mathrm{x}}$. On the other hand, it is more difficult to guarantee the control of the combustion timing, which is very sensitive to the thermodynamic conditions of the combustion chamber. The final objective, that has to be verified in a wide range of operating points, is to achieve a better combustion stability and control with the feed-forward black box ignition delay model of the pilot injection. 


\section{Engine characteristics}

The Diesel engine used in the experimental campaign is a turbocharged Diesel engine, equipped with a Common-Rail Multi-Jet injection system (designed to operate at injection pressures up to 1600 bar), mainly composed of a high-pressure volumetric pump, the fuel rail and 4 solenoid injectors, directly connected to the rail. The main technical characteristics of the engine under investigation are summarized in Table 1.

TABLE 1. Common Rail Diesel engine characteristics.

\begin{tabular}{|ll|ll|}
\hline Displacement volume: & $1248 \mathrm{~cm}^{3}$ & Bore: & $66 \mathrm{~mm}$ \\
Torque: & $200 \mathrm{Nm} @ 1500 \mathrm{rpm}$ & Stroke: & $82 \mathrm{~mm}$ \\
Power: & $70 \mathrm{~kW} @ 3800 \mathrm{rpm}$ & Compression ratio: & 16.8 \\
Valves: & 4 for cylinder & Architecture: & L4 \\
Firing Order: & $1-3-4-2$ & & \\
\hline
\end{tabular}

To analyze the behavior of pilot injections of gasoline, a complete new high-pressure injection system has been set up and directly connected to the Diesel solenoid injector of cylinder 1 . The additional fuel system, which consists of a supplementary volumetric pump (kept in motion by the crankshaft) and a new high-pressure rail for gasoline, is controlled using a programmable Rapid Control Prototyping (RCP) system, based on a National Instruments cRio 9082, managing the rail pressure and injections timing. Rail pressure control is performed varying the pulse width modulation (PWM) command of a solenoid bypass valve which recirculates gasoline upstream the volumetric pump (the duty cycle of the PWM is varied according to the difference between target and measured rail pressure). To manage injection timing, the RCP continuously updates the angular position of the crankshaft processing the crankshaft speed sensor signal and, according to that measurement, outputs the logical commands for the solenoid injector, i.e. SOI and Energizing Time (ET). These commands are communicated via CAN bus to the standard ECU for engine control, which converts the logical commands into electric commands for the injector.

The cylinder fueled with gasoline was equipped with a piezo-electric pressure transducer facing the combustion chamber and connected to a charge amplifier to obtain the pressure trace, and an inductive sensor facing the sensor wheel with 60-2 teeth was used to phase the pressure signal. Cylinder pressure and the signal coming from the pick-up faced to the sensor wheel have been sampled at $200 \mathrm{kHz}$ using a NI acquisition board, and in parallel also the data of pressure and temperature in the intake manifold and the temperature at the inlet of the turbine were acquired $(100 \mathrm{~Hz})$. Figure 1 shows a scheme of the experimental layout.

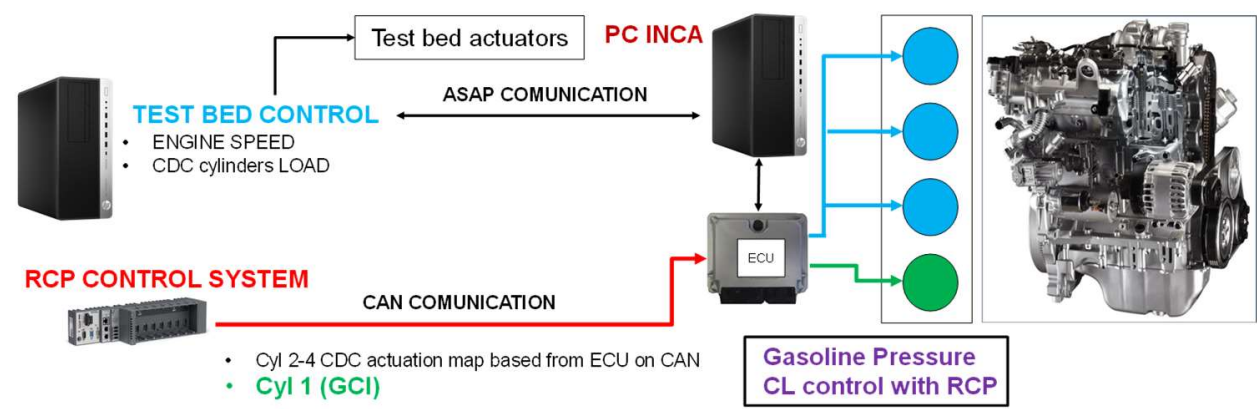

Fig. 1. Experimental layout

The tests have been carried out with the instrumented cylinder 1 fed only with the gasoline pilot injection, while the other three cylinders were run in normal Diesel mode assuring the 
working conditions, in terms of boost pressure, temperature and engine speed, listed in table 2. The pilot injection was performed varying the start of injection from $10^{\circ} \mathrm{BTDC}$ to $50^{\circ}$ BTDC with a constant mass of gasoline of $4 \mathrm{mg} / \mathrm{stroke}$.

TABLE 2. Engine experimental conditions.

\begin{tabular}{|l|l|l|l|l|l|}
\hline Test number & $\begin{array}{l}\text { Boost pressure } \\
{[\mathrm{bar}]}\end{array}$ & $\begin{array}{l}\text { Boost temperature } \\
{\left[{ }^{\circ} \mathrm{C}\right]}\end{array}$ & $\begin{array}{l}\text { Engine speed } \\
{[\mathrm{rpm}]}\end{array}$ & Prail [bar] & $\begin{array}{l}\text { Injected } \\
\text { gasoline } \\
{[\mathrm{mg} / \mathrm{stroke}]}\end{array}$ \\
\hline 1 & 1.45 & 75 & 2000 & 300 & 300 \\
\hline 2 & 1.55 & 20 & 2000 & 300 & 300 \\
\hline 3 & 1.45 & 75 & 2000 & 300 & 300 \\
\hline
\end{tabular}

\section{Combustion delay model structure}

\subsection{Fluid thermodynamic condition estimation at SOI angular position}

From here on the time delay between the SOI and the SOC of the pilot injection in the instrumented cylinder fueled with gasoline will be referred to as the "combustion delay".

Since the combustion delay is very sensitive to the thermodynamic conditions corresponding to the SOI, it has been decided that the black box model has to be related with the pressure and temperature at the SOI.

To estimate the thermodynamic condition of the fluid inside the cylinder at SOI it is necessary to evaluate pressure and temperature inside the cylinder in correspondence of the intake valve closing. This evaluation has been made taking into account the mass of air estimated by the ECU for a cylinder $\left(\mathrm{M}_{\mathrm{cyl}}\right)$ and the mass of exhaust gas remaining inside the combustion chamber $\left(\mathrm{M}_{\mathrm{exh}}\right)$ at the end of the exhaust phase, evaluated by means of the equation (1).

$$
\mathrm{M}_{\mathrm{exh}}=\frac{\mathrm{V}_{0} * \mathrm{p}_{\text {mean_exh }}}{\mathrm{R}_{\text {air }} * \mathrm{~T}_{\text {inlet turbine }}}
$$

Where $\mathrm{V}_{0}$ is the volume of the combustion chamber, $\mathrm{p}_{\text {mean }}$ exh is the mean pressure during the exhaust stroke evaluated within the angular position $620^{\circ}$ and $680^{\circ}$, considering as a reference $\left(0^{\circ}\right)$ the gas-exchange TDC. $\mathrm{R}_{\text {air }}$ is the air gas constant and $\mathrm{T}_{\text {inlet turbine }}$ the temperature of the exhaust gas at the turbine inlet, assumed representative of the temperature inside the combustion chamber.

Once the total mass trapped inside the cylinder $\left(\mathrm{M}_{\mathrm{IVC}}\right)$ at the intake valve closing (IVC) is known, given by the sum of $\mathrm{M}_{\mathrm{cyl}}$ and $\mathrm{M}_{\mathrm{exh}}$, setting $\mathrm{p}_{\mathrm{IVC}}$ to the turbocharger outlet pressure, the temperature $\mathrm{T}_{\mathrm{IVC}}$ can be determined by means of the ideal gas law.

As a last passage, the evaluation of $\mathrm{p}_{\text {SOI }}$ and $\mathrm{T}_{\text {SOI }}$ can be done starting from $\mathrm{p}_{\mathrm{IVC}}$ and $\mathrm{T}_{\text {IVC }}$ and taking into account the link between respectively pressure and temperature with volume during a polytropic compression from IVC to SOI, to which has been assigned the representative exponent value or 1.32, according the well-known equations (2).

$$
\mathrm{p}_{\mathrm{SOI}}=\mathrm{p}_{\mathrm{IVC}}\left(\frac{\mathrm{V}_{\mathrm{SOI}}}{\mathrm{V}_{\mathrm{IVC}}}\right)^{1.32} \quad \text { and } \quad \mathrm{T}_{\mathrm{SOI}}=\mathrm{T}_{\mathrm{IVC}}\left(\frac{\mathrm{V}_{\mathrm{SOI}}}{\mathrm{V}_{\mathrm{IVC}}}\right)^{(1.32-1)}
$$

where $\mathrm{V}_{\text {IVC }}$ and $\mathrm{V}_{\text {SOI }}$ are, respectively, the volume inside the cylinder at IVC and SOI. 
The application of the equations (2) can be used to evaluate the pressure and temperature trends in motoring condition, as can be seen from Figure 2.To identify the SOC angular position of the pilot injection the analysis of the rate of heat release has been carried out analyzing the pressure trace, as it will be described in the next paragraph.

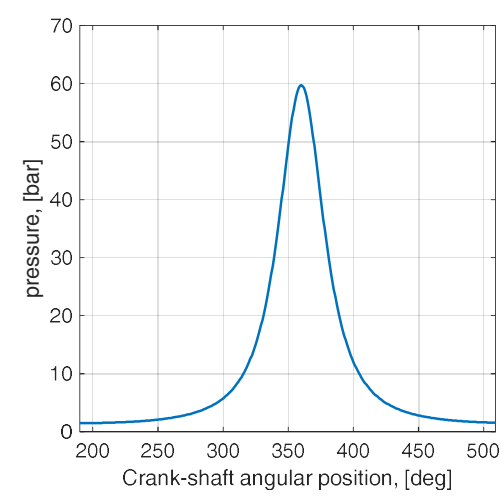

(a)

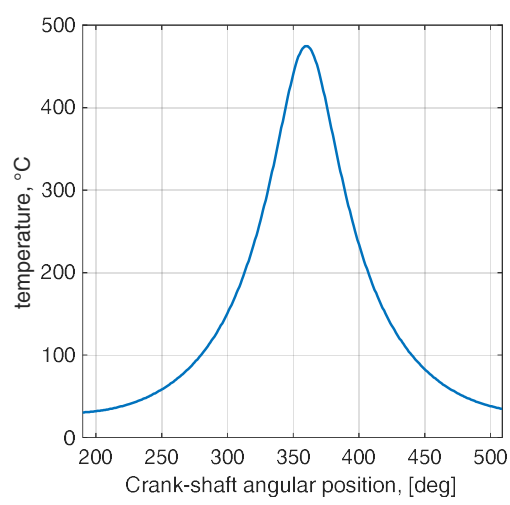

(b)

Fig. 2. Motoring pressure and temperature trends based on the polytropic thermodynamic model.

\subsection{Combustion delay experimental evaluation}

The evaluation of the combustion delay requires the determination of the angular position related to the combustion start of pilot injection.

In particular, from the pressure trace acquired inside the cylinder can be first determined the Rate of Heat Release (RoHR), reported in equation 3), and then the Cumulative Heat Release (CHR), by integration of the RoHR trend.

$$
R o H R=\frac{1}{\gamma-1}\left(V \cdot \frac{d p}{d \theta}+\gamma \cdot p \cdot \frac{d V}{d \theta}\right)
$$

In this case, due to the very low gasoline quantity interested in the combustion process, the location of the SOC is not trivial. Figure 3 shows the pressure trend of a combustion with the gasoline cylinder running at $2000 \mathrm{rpm}, 1.55$ bar of boost pressure and $75^{\circ} \mathrm{C}$ of outlet compressor temperature and $4 \mathrm{mg} /$ stroke of gasoline introduced with the pilot injection with SOI set to 34 degrees BTDC.

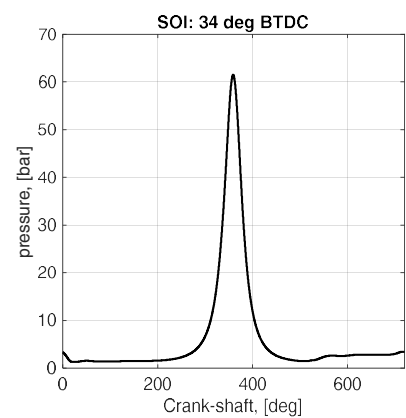

(a)

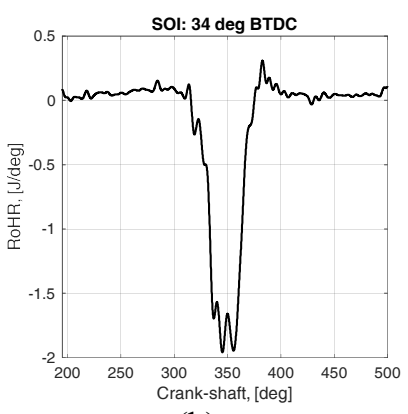

(b)

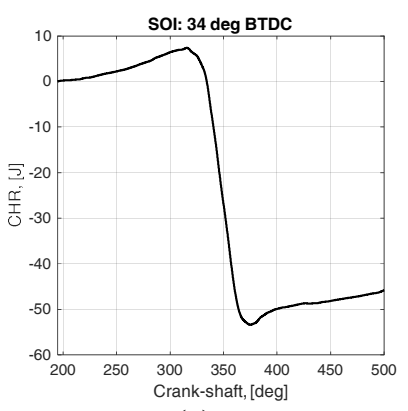

(c)

Fig. 3. Pressure trace (a), rate of heat release (b) and cumulative heat release (c) at start of pilot injection at $34 \mathrm{deg}$ BTDC. 
From the latter curve is it evident that the start of combustion is hidden in the descendent part of the Rate of Heat Release together with other effects, related to the heat exchange with the cylinder walls and the evaporation of injected gasoline, thus the delay cannot be identified with sufficient precision.

To overcome this problem a motoring cycle referring to the same cylinder running in the same boundary conditions of the previous test has been used, to cancel the effects hiding the heat release. Figure 4 shows the same trends presented in figure 3 (a) and (b) where the pressure and RoHR traces of the motoring cycle have been added, while figure 4 (c) shows the difference between the RoHR of the cylinder running with SOI at $34 \mathrm{deg}$ BTDC and in motoring condition.

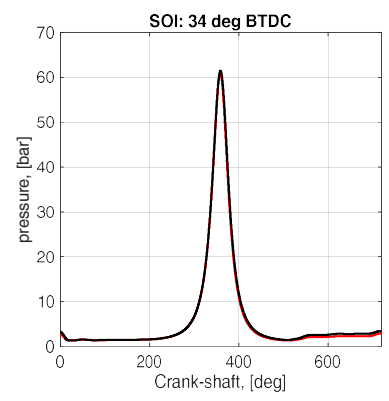

(a)

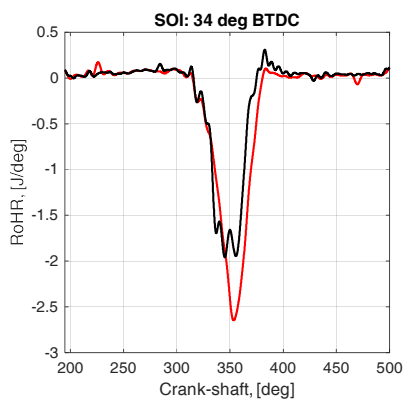

(b)

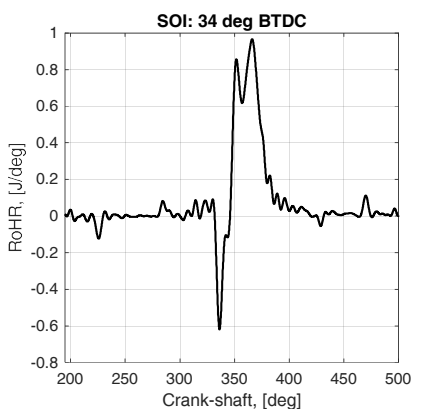

(c)

Fig. 4. Pressure trace (a), rate of heat release (b) of the engine running with $4 \mathrm{mg} / \mathrm{stroke}$ of gasoline injected at SOI $34 \mathrm{deg}$ BTDC (in black) and in motoring condition (in red). (c) Gross RoHR that highlight evaporation and combustion phases, obtained by the difference between the black and red trend of figure (b).

Integrating the RoHR of Figure 4 (c) it is possible to determine the start of combustion (SOC) of the pilot injection, identified as the angular position where the $10 \%$ of the mass fuel burned (MFB10) is reached.

In Figure 5, the cumulative heat release related to Figure 4 (c) is shown, with three vertical line corresponding respectively to MFB10 (green line), MFB50 (red line) and MFB90 (blue line).

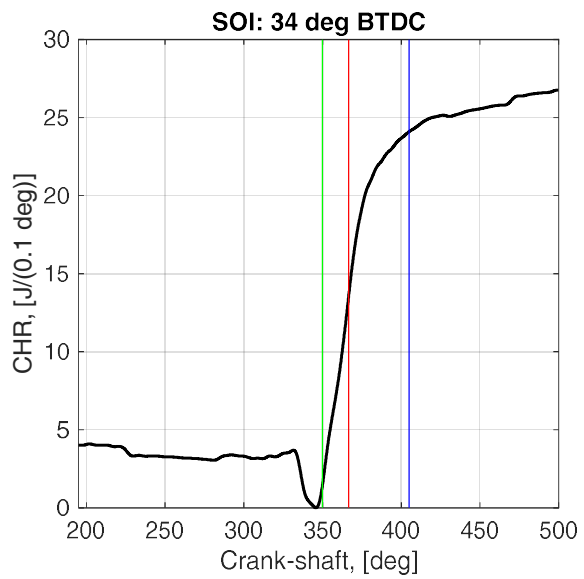

Fig. 5. Cumulative heat release related to Figure 4 (c). 
The angular combustion delay can then be evaluated from the angular distance between the SOC and the SOI and then with the following equation 4) the combustion time delay can be evaluated:

$$
\tau_{m}[\mathrm{~ms}]=\frac{\text { SOI }[\operatorname{deg} \text { BTDC }]-\text { MFB10 }[\operatorname{deg} \text { ATDC }]}{\mathrm{n}_{\text {engine }}[\mathrm{rpm}]} \frac{1000}{6}
$$

The following Figure 6 shows the angular delay (between MFB10 and SOI) as a function of SOI, for the tests carried out with the boost pressure of 1.55 bar and boost temperature of 75 ${ }^{\circ} \mathrm{C}$.

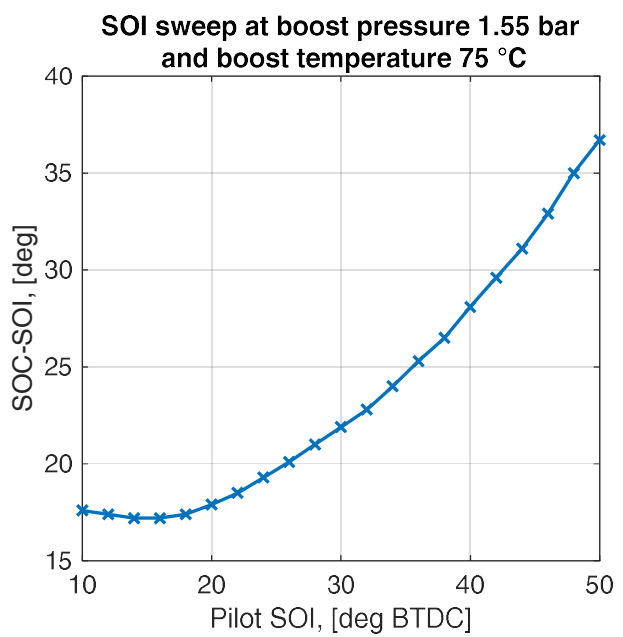

Fig. 6. Angular combustion delay in function of SOI.

Figure 7 compares SOI pressure (a) and temperature (b) trends evaluated using the cylinder pressure information, with those obtained determining first the total mass trapped in the cylinder at IVC and then applying the polytropic compression from IVC to SOI, as previously described.

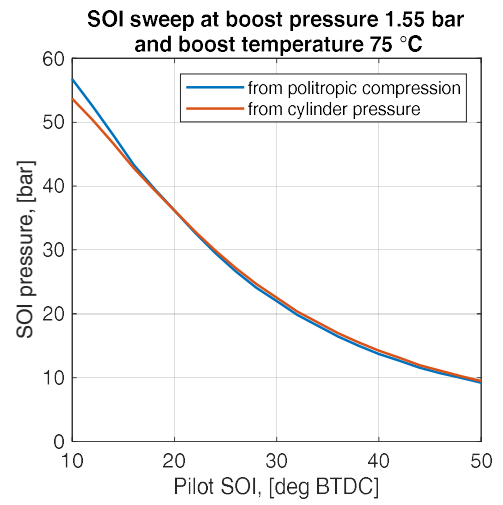

(a)

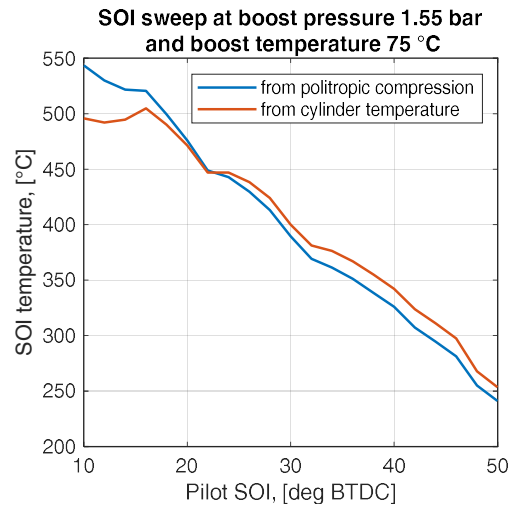

(b)

Fig. 7. In (a) comparison of the SOI pressure evaluated by the polytropic compression and from the in-cylinder pressure, and in (b) the same for the SOI temperature. 


\section{Results}

Three tests, whose conditions are reported in Table 2, have been carried out in the Dieselgasoline fueled engine where the combustion delay has been related to the pressure and temperature at pilot SOI angular position with the engine running in steady-state conditions and with a gasoline injection of $4 \mathrm{mg} / \mathrm{stroke}$ (the typical gasoline quantity used to determine the ignition of the partially premixed gasoline combustion) in absence of the main injection. The tests have been carried out utilizing a single cylinder of the engine running with only the gasoline pilot injection, while the other three cylinders were run in standard Diesel mode. The data related to the angular delay between SOC and SOI have been evaluated, as described in the previous paragraph, as a function of the SOI pressures and temperatures. This allows to obtain the reference three-dimensional map shown in Figure 8, representing the black box model of the combustion delay. Even if the tests have been done in a limited range of the operating engine running conditions for the cylinder with the gasoline pilot injection, the clean trend of the samples suggests that wider operating range would lead to a smooth surface.

In this case the injection pressure has been maintained at the constant value of 300 bar. Future tests will be carried out with the aim of highlighting the influence of the injection pressure on the combustion delay map.

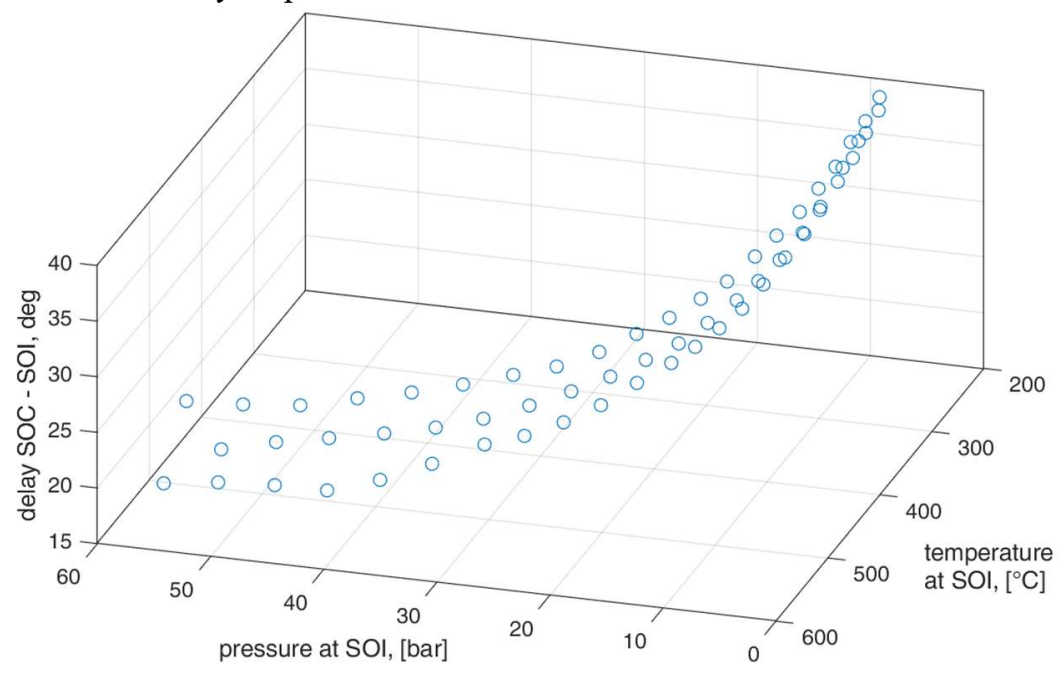

Fig. 8. Combustion delay map with the engine running at $\lambda=1$ in function of pressure and temperature at pilot SOI

In the operative implementation of this procedure to close the control loop it is necessary to determine the angular position of the MFB50 of the main injection. An interesting potential solution is the use of piezoelectric washer sensors (16) placed in correspondence of the injector screw thread. Figure 9 (a) shows the pressure traces acquired with a miniaturized lab-grade piezoelectric sensor placed in the combustion chamber and that obtained with the washer sensor. Figure 9 (b) reports the RoHR obtained from the pressure data of figure 9 (a), in order to compare the estimation of the angular position of the start of combustion gathered with the two sensors. It can be seen that the correlation between the two signals is good enough to accurately evaluate the MFB50 angular position. 


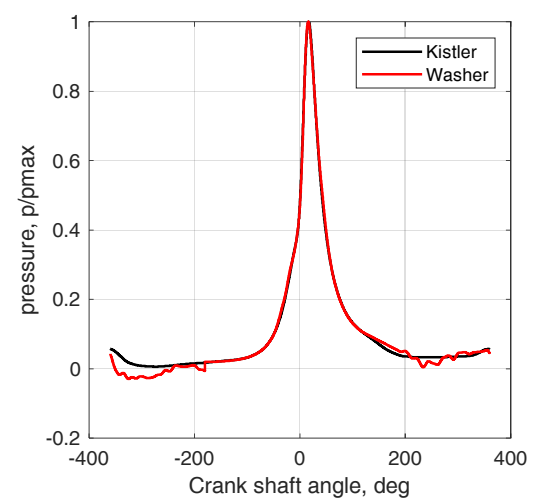

Fig. 9 (a). Comparison of the pressure trace acquired by means a piezo-electric transducer facing the combustion chamber and the piezoelectric washer in correspondence of the fuel injector.

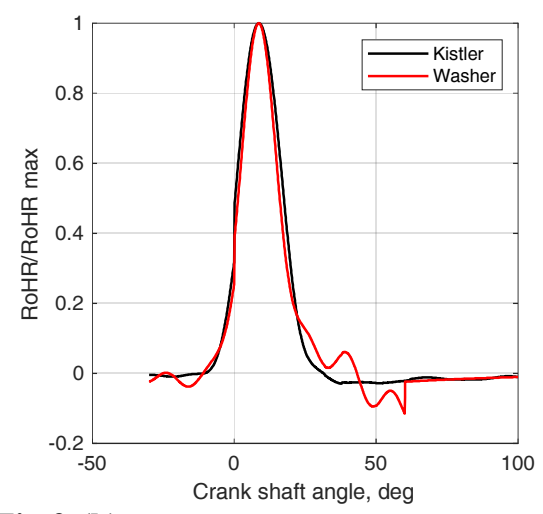

Fig.9 (b). Comparison of the RoHR evaluated by means of the pressure traces of Figure 9 (a).

\section{Conclusions}

The paper presents the experimental determination of combustion delay black box models represented in the form of a map in function of the pressure and temperature in correspondence of the position where the pilot injection is performed.

The experimental tests have been carried out in a Diesel engine fueled with gasoline pilot injections in one cylinder in order to obtain information that can be utilized by the control strategies to estimate the combustion delay between the start of the pilot injection and the start of the combustion. The final aim is to utilize this map in real time when the engine will be completely fueled by gasoline in order to obtain an advance estimation of the possible angular position of the pilot injection so to enhance the control of the angular position of the main combustion.

\section{Nomenclature}

\section{BTDC \\ CHR \\ ECU \\ ET \\ GDCI \\ IVC \\ LTC \\ $\mathrm{M}_{\mathrm{cyl}}$ \\ $\mathrm{M}_{\mathrm{exh}}$}

MFB10, 50, 90

fuel has burned

$\mathrm{M}_{\mathrm{IVC}}$

$\mathrm{NO}_{\mathrm{x}}$

pIVC

pmean_exh

psOI
Before Top Dead Center

Cumulative heat Release

Electronic control Unit

Energizing Time

Gasoline Direct injection Compression Ignition

Intake Valve Closing angular position

Low Temperature Combustion

Air mass in the cylinder at the end of the intake phase

Exhaust gas remaining in the cylinder combustion chamber

Angular position where the $10 \%, 50 \%$ and $90 \%$ of the total mass of

Total Mass trapped in the cylinder at IVC

Nitrogen Oxides

Pressure inside the cylinder at IVC

Mean pressure inside the cylinder during the exhaust stroke

Pressure at SOI 


$\begin{array}{ll}\text { PWM } & \text { Pulse Width Modulation } \\ \mathrm{R}_{\text {air }} & \text { Gas constant for air } \\ \text { RCP } & \text { Rapid Control Prototyping } \\ \text { RoHR } & \text { Rate of Heat Release } \\ \text { SOC } & \text { Start Of Combustion } \\ \text { SOI } & \text { Start Of Injection } \\ \mathrm{T}_{\text {inlet turbine }} & \text { Temperature at the inlet side of the turbine } \\ \mathrm{T}_{\text {IVC }} & \text { Temperature inside the cylinder at IVC } \\ \mathrm{T}_{\text {SOI }} & \text { Temperature at SOI } \\ \text { TDC } & \text { Top Dead Center } \\ \mathrm{V}_{0} & \text { Volume of the combustion chamber } \\ \mathrm{V}_{\text {IVC }} & \text { Volume inside the cylinder at IVC } \\ \mathrm{V}_{\text {SOI }} & \text { Volume inside the cylinder at SOI }\end{array}$

\section{References}

1. M Torregrosa, A.J.; Broatch Jacobi, J.A.; García Martínez, A.; Monico Muñoz, L.F. (2013). "Sensitivity of combustion noise and NOx and soot emissions to pilot injection in PCCI Diesel engines," Applied Energy. 104:149-157. https://doi.org/10.1016/j.apenergy.2012.11.040.

2. Kolbeck, A.F., "Closed Loop Combustion Control - Enabler of Future Refined Engine Performance Regarding Power, Efficiency, Emissions \& NVH under Stringent Governmental Regulations", SAE Technical Paper 2011-24-0171, 2011, https://doi.org/10.4271/2011-24-0171.

3. Li, C., Xu, L., Bai, X.-S., Tunestal, P. et al., "Effect of Piston Geometry on Stratification Formation in the Transition from HCCI to PPC," SAE Technical Paper 2018-01-1800, 2018, https://doi.org/10.4271/2018-01-1800.

4. Dempsey, A. B., Curran, S. J., \& Wagner, R. M. (2016). A perspective on the range of gasoline compression ignition combustion strategies for high engine efficiency and low NOx and soot emissions: Effects of in-cylinder fuel stratification. International Journal of Engine Research, 17(8), 897-917. https://doi.org/10.1177/1468087415621805.

5. Kimura, S., Aoki, O., Kitahara, Y., and Aiyoshizawa, E., "Ultra-Clean Combustion Technology Combining a Low-Temperature and Premixed Combustion Concept for Meeting Future Emission Standards," SAE Technical Paper 2001-01-0200, 2001, https://doi.org/ 4271/2001-01-0200.

6. Belgiorno, G., Dimitrakopoulos, N., Di Blasio, G., Beatrice, C., Tunestål, P., Tunér, M., "Effect of the engine calibration parameters on gasoline partially premixed combustion performance and emissions compared to conventional diesel combustion in a light-duty Euro 6 engine", Applied Energy, Volume 228, 2018, Pages 2221-2234, ISSN 03062619, https://doi.org/10.1016/j.apenergy.2018.07.098.

7. Belgiorno, G., Dimitrakopoulos, N., Di Blasio, G., Beatrice, C. et al., "Parametric Analysis of the Effect of Pilot Quantity, Combustion Phasing and EGR on Efficiencies of a Gasoline PPC Light-Duty Engine," SAE Technical Paper 2017-24-0084, 2017, https://doi.org/10.4271/2017-24-0084.

8. Leermakers, C., Somers, L., and Johansson, B., "Combustion Phasing Controllability with Dual Fuel Injection Timings," SAE Technical Paper 2012-01-1575, 2012, https://doi.org/10.4271/2012-01-1575.

9. Ravaglioli, V., Ponti, F., De Cesare, M., Stola, F. et al., "Combustion Indexes for Innovative Combustion Control," SAE Int. J. Engines 10(5):2371-2381, 2017, https://doi.org/10.4271/2017-24-0079. 
10. Gentz, G., Dernotte, J., Ji, C., and Dec, J. "Spark Assist for CA50 Control and Improved Robustness in a Premixed LTGC Engine Effects of Equivalence Ratio and Intake Boost," SAE Technical Paper 2018-01-1252, 2018, https://doi.org/10.4271/2018-01-1252.

11. An, Y., Mubarak Ali, M.J., Vallinayagam, R., AlRamadan, A. et al., "Compression Ignition of Low Octane Gasoline under Partially Premixed Combustion Mode," SAE Technical Paper 2018-01-1797, 2018, https://doi.org/10.4271/2018-01-1797.

12. Matsuura, K. and Iida, N., "Effect of Temperature-Pressure Time History on AutoIgnition Delay of Air-Fuel Mixture," SAE Technical Paper 2018-01-1799, 2018, https://doi.org/10.4271/2018-01-1799.

13. Leermakers, C., Bakker, P., Somers, L., de Goey, L. et al., "Butanol-Diesel Blends for Partially Premixed Combustion," SAE Int. J. Fuels Lubr.6(1):217-229, 2013, https://doi.org/10.4271/2013-01-1683.

14. Ravaglioli, V. and Bussi, C., "Model-Based Pre-Ignition Diagnostics in a Race Car Application,” Energies, MDPI, Open Access Journal 12(12):1-12, June 2019.

15. Ravaglioli V., Ponti F., De Cesare M., "Investigation of Gasoline Compressione Ignition for Combustion Control", 2019, ASME Internal Combustion Engine Division Fall Technical Conference.

16. Corti, E., Abbondanza, M., Ponti, F., and Raggini, L., "The Use of Piezoelectric Washers for Feedback Combustion Control," SAE Technical Paper 2020-01-1146, 2020, https://doi.org/10.4271/2020-01-1146. 